\title{
UNA SOCIEDAD DUAL. LAS COMARCAS DE CASTELLÓ ENTRE LA VIEJA Y LA NUEVA POLÍTICA
}

\author{
Eduardo Pérez Arribas
}

El sistema político imperante en el último tercio del siglo XIX en España ha sido descrito por diversos autores como predemocrático ${ }^{1}$. Por su propia definición, este término nos indica que estamos ante un período de crisis, de tránsito. Así, la vieja política, es decir, la praxis que consagró el liberalismo doctrinario y que encumbró a la burguesía moderada en el poder, comienza a presentar fisuras al tiempo que emergen los valores y principios democráticos empujados por una nueva burguesía ascendente y por las clases populares.

Pero en el ámbito de la evolución política los elementos modernos fueron imponiéndose de una manera pausada y gradual, siendo en muchos casos la existencia de condiciones socio-económicas distintas a las tradicionales las que permitieron que aquellas acabaran triunfando.

Por tanto, cabe decir que durante el período de la Restauración existe una sociedad dual que, en el caso de las comarcas de Castelló, se materializa tanto a nivel territorial, -predominio de lo tradicional en las áreas rurales, mayor influencia de elementos modernos en la capital-, como en el comportamiento de las fuerzas políticas y sociales.

Políticos-caciques y partidos que movilizan la opinión convivieron en la política castellonense de finales del XIX, compartiendo elementos propios de la nueva política al tiempo que continuaban haciendo uso de mecanismos de la vieja.

A lo largo del presente trabajo podrá apreciarse como lo viejo y lo nuevo se acoplan en la evolución y en el comportamiento político, tanto de la élite dirigente como de su oposición, dando fisonomía propia a un período de transición en el que lo remarcable no es la persistencia de elementos premodernos ${ }^{2}$, sino el avance de unas nuevas pautas de comportamiento político que responden a una nueva realidad socio-económica y cultural que va asentándose progresivamente y que dará como resultado la crisis misma del sistema de la Restauración, ante la imposibilidad por parte de sus dirigentes de combatir con los viejos preceptos las tendencias emergentes.

Antes de comenzar a valorar la evolución del comportamiento de las fuerzas

\footnotetext{
${ }^{1}$ Uno de los primeros en utilizar coherentemente el término referido a este período fue TUSELL, J.: Oligarquía y caciquismo en Andalucía (1890-1923) (Barcelona, 1976), p. 13. Más recientemente, CARNERO, T. y PALAFOX, J.: Creixement, politització i canvi social, 1790-1980 (Valencia, 1990), p. 40

${ }^{2}$ Contrariamente a lo que asegura MAYER, A. J.: La persistencia del Antiguo Régimen (Madrid. 1984), p. 16.
} 
políticas, es necesario distinguir entre dos realidades con un grado de permeabilidad muy diferente respecto de los elementos modernos.

En lo que respecta a la ciudad de Castello, su estratificación social y su rango administrativo, como capital provincial, le confieren un carácter más dinámico y abierto. La población agrícola convive con artesanos, algunos semiproletarizados ya, con personas que trabajan en la administración y en profesiones liberales. Es una clase media urbana cuyos gustos e ideologías resultan más progresistas y avanzados respecto de los de la población dedicada al sector agrario. Refuerza este factor de diferenciación social la presencia de las instituciones propias del rango de capitalidad, la prensa, los intelectuales y sus círculos de actuación, que constituyen otros tantos foros que contribuyen a renovar la atmósfera socio-política. Todo ello confirió a Castelló unos rasgos políticos distintos a los de las poblaciones que encabezaba, arraigándose tendencias ideológicas que poco tenían que ver con los moldes tradicionales, predominantes en los pueblos de la provincia, y desvinculándose mucho antes de los caciques.

Fuera de la capital la inmensa mayoría de los labradores, propietarios y arrendatarios, poseían un comportamiento más tradicional y más desmovilizado políticamente ${ }^{3}$. El temor a perder sus tierras o sus buenas condiciones de arrendamiento fue un factor decisivo en la sumisión política del labrador al cacique y que explica la base del consenso sobre la que éste hizo efectivo su poder, ya que es visto como representante de un régimen que ofrecía un mínimo de seguridades jurídicas ${ }^{4}$.

El esquema que se desprende del análisis político de las comarcas castellonenses en el último tercio del siglo XIX responde, igualmente, a las características de una sociedad dual y en proceso de transición. Así, la fracción políticamente dirigente se aprovechó de tal evolución, simplificando la vida política y reduciendo las posibilidades de los excluidos que, como veremos, se convirtieron en seguidores de partidos marginales 0 , simplemente, en manipulados votantes al servicio del sistema.

Esta situación tiene su origen en el concepto patrimonial que la élite dirigente tenía del gobierno de la provincia, factor que contribuyó a frenar la modernización política en Castelló ${ }^{5}$. Esta élite, agrupada en torno a la asociación caciquil conocida con el nombre de "cossi", -cliente política del duque de Tetuán y liderada en la provincia por la familia Fabra-, hizo todo lo posible por evitar el turno en la provincia, monopolizando el poder durante prácticamente todo el período estudiado. Su estrategia fue la de cambiar de partido, en un intento de aparecer siempre como

\footnotetext{
${ }^{3}$ Los arrendatarios compartirían con los propietarios su actitud ante lo tradicional debido a que las condiciones de sus arriendos eran muy benignas, incluso solían ser hereditarios, lo que les equiparaba a los propietarios. Cf. GARRABOU, R.: Un fals dilema. Modemitat o endarreriment de l'agricultura valenciana, 1850-1900 (Valencia, 1985). p. 141.

${ }^{4}$ En los núcleos rurales nos encontramos ante una persistencia bastante extendida de la legitimidad basada en la costumbre, según la terminologia weberiana. Una visión similar para el caso de Sabadell Cf. RANZATO, G.: La aventura de una ciudad industrial. Sabadell entre el Antiguo Régimen y la modernidad (Barcelona, 1987), p. 34

${ }^{5}$ Ese concepto patrimonial era común también en la élite dirigente nacional. Cf. CARNERO, T.: "Política sin democracia en España, 1874-1923", Revista de Occidente, 83 (1989) 48.
} 
situacionistas, con lo que oscilaron entre ambos partidos dinásticos entre 1876 y $1897^{6}$. Su desideologización, propia de la vieja política, no era un signo de modernización, como tampoco lo era el hecho de que su actitud al frente de la administración provincial estuviera más marcada por su deseo de conservar el poder que por defender los intereses económicos de la provincia. Como caciques sólo estaban obligados por vínculos de carácter personal, no dependían de los intereses económicos colectivos de sus electores. Es así como se explica la colaboración del cossi con los intereses proteccionistas, aún cuando los suyos propios pudiesen ser librecambistas, como lo eran los de los castellonenses en general ${ }^{7}$. El apoyo al proteccionismo era la contrapartida que el cossi había de pagar al gobierno por asegurarle éste el control político de la provincia. Otro ejemplo de cómo los tetuanistas dieron la espalda a los intereses económicos provinciales fue el de la construcción del puerto de Castelló, cuyas obras retrasaron, lo que les enfrentó con la movilización popular, dirigida por los republicanos.

El apego de estos políticos profesionales al poder reside en que es a éste a quien deben su posición y fortuna. Al frente de la administración local y provincial realizaron toda una serie de negocios, legales o no, que les convirtieron, ya antes del sexenio, en una importante élite económica, poseedora de tierras y conectada con los más altos ambientes administrativos.

Como consecuencia de la extracción social y de los intereses económicos de la élite dirigente cabe deducir una hegemonía de lo rural y provincial sobre lo urbano, simbolizado por la capital y sus fuerzas políticas progresistas. Ese dominio sobre la ciudad se materializa a través de tres conductos: por la presencia física de los prohombres cossieros en la ciudad, es decir, viven allí; por su vinculación con las familias de Castello; y por las presiones sobre funcionarios públicos de instituciones de la capital.

El dominio de lo rural sobre lo urbano, es decir, el hecho de que el sistema político dependa más del apoyo del campo que del de la ciudad, es también un rasgo de no modernización política, según Huntington, si bien el crecimiento de la ciudad se convierte en un fenónemo desestabilizador, reflejo de un curso de modernización global$^{9}$. Este sería el caso de Castelló a finales del siglo XIX, constituyendo, por

\footnotetext{
${ }^{6}$ Los tetuanistas militaron en el Partido Liberal Conservador en una primera etapa desde 1874 a 1881 . Tras unos años de militancia en el Partido Liberal, 1881-1890, volvieron a aquel en este último año hasta la muerte de Cánovas en 1897. A partir de entonces se autodefinieron como Conservadores independientes o, simplemente, tetuanistas, ya que el duque se proclamó heredero de la tradición de Cánovas y se negó a entrar en el Partido Conservador presidido por Silvela. Cf. PÉREZ ARRIBAS, E.: Politics $i$ cacis a Castelló, 1876-1901 (Valencia, 1988). p. 16.

${ }^{7}$ En el seno de la familia Fabra, dirigentes del cossi, no faltan personas, como Plácido Fabra Adelantado, que, además de sus propiedades territoriales, poseía un negocio de "especulación en frutos" Cf. Archivo Municipal de Vila-real (A.M.V.) Libros de Administración $n^{9} 1.242$.

${ }^{8}$ La relación y descripción de algunos de estos negocios se encuentra en la prensa de la epoca, que puede consultarse en el Archivo Municipal de Castelló (A.M.C.).

9 Citado por DUNCAN. J.: "Peasant society and clientelist politics". American Political Science Review, LXIV (1970) 422.
} 
tanto, un componente que ayuda a definir la dualidad del período.

La ruralización de la vida política era debida a la presencia de un fuerte aparato caciquil que monopolizaba el poder en la provincia. Pero ello no hubiera sido posible sin el consenso de la misma población rural. Este se consiguió a base de regular la escasez de recursos. Esta escasez era derivada de un proceso incompleto de modernización económica. Para que éste se produzca es necesario un aumento sustancial de los sectores secundario y terciario ${ }^{10}$. Sin embargo, la población se dedicaba en sus tres cuartas partes a la agricultura, mientras que muchos jóvenes con estudios encontraban dificultades para conseguir trabajo en la ciudad ${ }^{11}$. De esta forma, la concesión de empleos y cargos se convirtió en uno de los principales instrumentos del aparato caciquil para atraerse adhesiones. Varela Ortega ha denominado a este tipo de relación entre el cacique y su clientela basada en el intercambio de favores "caciquismo transicional y apoyo por compensación concreta". Este modelo supone una cierta irrupción del medio urbano en el campo, ya que el cacique debe toda su fuerza a su posición al frente de las instituciones ubicadas en la ciudad, desde las que puede subvenir a numerosas necesidades de carácter administrativo de los campesinos. También está ligado al fenómeno de la "empleomanía", propio del modelo de instituciones premodernas que escogen su personal en función de la influencia, en lugar del sistema de méritos ${ }^{12}$.

Por tanto, la relación entre el grupo dirigente y sus electores se basó en el clientelismo. La forma en que los amigos de Fabra, -y también sus opositores dinásticos cuando ocupan el poder-, obtienen los apoyos políticos coincide con lo descrito por diversos autores para definir la relación entre un individuo, patrón, de alto estatus socio-económico, que usa su influencia y recursos para proveer de protección o beneficios a una persona de bajo estatus, cliente, quien en reciprocidad le ofrece su apoyo y asistencia, normalmente en forma de votos en las elecciones ${ }^{13}$.

Ahora bien, ¿se comportaron como patrones tradicionales o modernos?. Según el modelo establecido por White, el clientelismo utilizado por el cossi es de tipo moderno, ya que el control se ejerce a través de su influencia en instituciones importantes, por el desempeño de profesiones influyentes y a través de los lazos políticos que establecían con empleados y sirvientes del gobierno en Madrid. El patrón tradicional, por el contrario, es aquel que ejerce su control gracias al acceso

${ }^{10}$ PALAFOX, J.: "Los límites de la modemización en España: la evolución económica entre 1892 y 1930", Revista de Occidente, 8 (1988) 60

${ }^{11}$ Sobre la educación y problemas de colocación Cf. AGUILAR, C.: La educación en Castellón a través de la prensa, 1868-1900 (Castelló, 1985).

${ }^{12}$ VARELA ORTEGA, J.: Los amigos políticos. Partidos, elecciones y caciquismo en la Restauración (1875-1900) (Madrid, 1972), pp. 360-361. El criterio empleado en la elección de su personal distingue las instituciones modemas de las premodernas. Cf. WHITE, C.: Patrons and partisans, a study of politics in two southerns Italian comuni. (Cambridge. 1980), p. 161.

${ }^{13}$ CHUBB. J.: Patronage, power and poverty in southern ltaly. A tale of two cities. (Cambridge, 1982), p. 4. 
y reparto de riquezas, caso que no es el general en Castello ${ }^{14}$. El clientelismo de tipo moderno es favorable al proceso de desarrollo y modernización, ya que facilita los vínculos entre la ciudad y sus instituciones con el medio rural ${ }^{15}$. Volviendo a Huntington, se trataría de un fenómeno reflejo en el cual la ciudad, sometida a una hegemonía política derivada del apoyo fundamental del medio rural, vuelve sobre éste ahora su influencia en un proceso largo que finalizará con la hegemonía de la ciudad sobre el campo cuando el proceso de modernización alcance su madurez.

Modelos aparte, el clientelismo político es un fenómeno premoderno. La organización política del tipo "patrón-cliente" se enmarca en un régimen parlamentario de sufragio censitario y con un débil papel del Estado, en un contexto de economía agraria tradicional, y en un sistema de partidos de notables, sin movilizaciones de masas y donde el apoyo se paga con beneficios de carácter personal ${ }^{16}$.

La reimplantación del sufragio universal masculino en 1890 no varió en nada este esquema. Por el contrario, excepto en el distrito electoral de Castello, el cossi reforzó sus posiciones, aumentando sus triunfos desde la oposición ${ }^{17}$. Por tanto, en las zonas rurales el sufragio universal no hizo sino aumentar la esfera de acción del cacique, aumentando su poder al tiempo que se generalizaba aún más la corrupción electoral, obstaculizándose la formación de una opinión pública ${ }^{18}$. Es significativo que el mayor número de denuncias por falseamiento de resultados se diese tras 1890 . Asimismo, el nivel de competitividad en las elecciones legislativas descendió tras esa fecha, sobre todo en las áreas rurales. Aquí el sufragio universal no aceleró el ritmo de modernización política, dada la importante implantación que poseía la máquina cossiera.

No ocurrió lo mismo en la ciudad de Castello, donde el sufragio universal vino a satisfacer la necesidad de expresión política de una parte de la población cuyos intereses socio-económicos no eran atendidos por el grupo político dominante. De todo ello se benefició el republicano Partido Demócrata Progresista. Pese a su carácter y voluntad interclasista, su plana mayor estaba formada por hombres pertenecientes a la élite profesional y comercial de la ciudad, -su carácter elitista se acentuó tras la muerte de Francisco González Chermá en 1896 y sus sustitución por Fernando Gasset en la jefatura del partido en la provincia-. Ello significaba que los republicanos iban a utilizar su base social contra el caciquismo para obtener mejoras que beneficiasen la expansión económica de la clase agromercantil que dirigía el partido. Así, el tema de la construcción del puerto de Castelló se convirtió en el símbolo para aquellos que luchaban por mejorar las infraestructuras de la provincia

\footnotetext{
${ }^{14}$ Aqui lo que se da es un trasiego de empleados a cada cambio de situación política, afectando, principalmente, a los de carácter municipal. Cf. PÉREZ ARRIBAS, E.: Los Ayuntamientos de la Restauración. El Ayuntamiento de Vila-real. 1877-1887. (Vila-real, 1991).

${ }^{15}$ WHITE, C.: op. cit. p. 161.

${ }^{16}$ CHUBB, J.: op. cit. p. 76.

${ }^{17}$ PÉREZ ARRIBAS, E.: Politics $i$ cacics .... op. cit. p. 93.

${ }^{18}$ DARDE, C.: "La implantación de la democracia en la España de la Restauración", Revista de Occidente, 50 (1985) 116-117.
} 
de cara a revitalizar sus negocios de exportación. La política dilatoria de los tetuanistas respecto a este tema dio a sus opositores uno de sus principales argumentos críticos: el caciquismo era el culpable de que la provincia no prosperase, ya que se encontraba más interesado en autoperpetuarse en el poder y en enriquecer a sus amigos políticos que en velar por los intereses generales de los castellonenses.

En la práctica se trataba de dos modos distintos de comportamiento político que respondían a tipos de organización política igualmente duales. Si el cossi podía clasificarse en el modelo "patrón-cliente", los republicanos estaban cercanos a un partido de masas. Como tal, se mostraban al servicio de una comunidad, identificada generalmente con las clases urbanas de la capital, y no al servicio de personas concretas, como es preceptivo en los partidos clientelísticos.Aunque en el fondo se velase por los intereses de la élite que dirigía el partido, su mensaje era interclasista. Así, en la campaña electoral para las legislativas de 1891 presentaban un auténtico programa en el que defendían principios que representaban intereses de diferentes colectivos sociales, como la autonomía municipal y regional, el librecambismo, la reforma de los tributos, la propiedad individual, el derecho de los obreros al trabajo y la responsabilidad de los funcionarios públicos, imprescindible para atajar los abusos administrativos cometidos por los agentes caciquiles ${ }^{19}$.

El mensaje de los republicanos, sin embargo, iba más allá de lo concreto. Significaba una vía de cambio en la concepción de la política. El partido no estaba formado estrictamente por políticos profesionales, sino por un colectivo que pretendía servirse de la política para hacer realidad sus proyectos de desarrollo económico, tan beneficiosos para la comunidad como para sus propios negocios. Ello fue posible gracias a su independencia de cualquier tipo de vínculo clientelístico. Como consecuencia, pudieron presentar siempre candidatos naturales del distrito y vinculados a él, convirtiéndose en los máximos detractores del cunerismo, al que achacaban todos los males de la provincia, huérfana, según ellos, de una auténtica representación política identificada con sus intereses.

El anticunerismo como vía para reivindicar el progreso se convirtió en uno de los núcleos del programa republicano. Se trataba de una apelación ética que encontró su idea movilizadora, -mito-, en el tema del puerto, como símbolo de progreso para una provincia cuya economía estaba centrada en la agricultura de exportación ${ }^{20}$. Este asunto fue, durante la época del reencuentro con el sufragio universal, el que concentró las energías morales de la multitud y dio lugar a movilizaciones populares que facilitaron la fusión de los intereses colectivos con los propios de la jerarquía republicana, teniendo siempre como enemigo común el caciquismo de los Fabra. No sería arriesgado, pues, tipificar en principio el comportamiento del republicanismo castellonense como populista, aunque tal definición deberá tomarse con reservas, como más adelante se verá, ya que presenta muchas concomitancias con el de los blasquistas valencianos, cuyo carácter populista ha dejado patente Ramiro Reig. Al igual que los blasquistas, los zorrillistas de Castelló se convirtieron en el partido de

${ }^{19} \mathrm{Cf}$. El Clamor de Castellón (18-1-1891) 2 y (29-1-1891) 1.

${ }^{20}$ Me baso en las caracteristicas del populismo según REIG, R.: "Populismes", Debats, 12 (1985) 6. 
la ciudad, y desde el control del Ayuntamiento, a partir de la última década del siglo, asumieron la representación del conjunto ciudadano.

Como demostración de esa voluntad interclasista, en 1901 republicanos y socialistas aún compartían mítines y se codeaban en las celebraciones del primero de mayo y en el aniversario de la Comuna de París, alardeando de un sentimiento revolucionario de dudosa sinceridad en el caso de los máximos dirigentes republicanos. En el mitin del primero de mayo, realizado en la plaza de toros, tras los líderes del incipiente socialismo local, tomaron la palabra algunos de los más destacados prohombres del republicanismo de la capital. Así, Fernando Gasset se consideró a si mismo como "un obrero de tantos", -en realidad se dedicaba a la abogacía como profesión-, significando que siempre prestaría su apoyo a la clase trabajadora. Después, Forcada Peris aseguró que siempre había estado a la vanguardia del movimiento de los trabajadores, y terminó diciendo que la revolución social era "la única que podía redimirnos"21. Es evidente que el republicanismo poseía un importante apoyo entre la clase obrera que no estaba dispuesto a perder en favor de los auténticos partidos de clase, como el socialista.

Por tanto, por su compromiso ideológico, vinculado a unos intereses económicos muy definidos, por su comportamiento político, -verdaderas campanas electorales, mítines y contenido programático, y por poseer un auténtico apoyo en la calle, el partido republicano representaba un grado de avance en la modemización política de Castello ciudad.

Sin embargo, no todo fue tan coherente en los republicanos. En 1893 llegaron a un acuerdo con los tetuanistas para repartirse en el futuro las áreas de influencia en las legislativas: el distrito de Castelló para los republicanos, que ya controlaban el Ayuntamiento de la capital, mientras el cossi se quedaba con el resto de distritos provinciales $^{22}$. Esta alianza con los tetuanistas representaba una concesión a la vieja política en pos de un doble objetivo: asegurarse el control de la ciudad de Castelló y conseguirse un buen aliado ante la avalancha carlo-católica que se avecinaba. Para el cossi suponía rendirse ante su incapacidad de vencer al republicanismo con su arma tradicional, el clientelismo, más ineficaz cuanto más se desarrollan los movimientos de opinión. Los republicanos se mostraron como hábiles manipuladores e instigadores de éstos, mientras los partidos del turno, no sólo no se adaptaron a ellos, sino que, además, intentaron hacerles frente ante el temor de que su hegemonía, basada precisamente en la desmovilización popular, corriese peligro.

Pero la derecha más reaccionaria encontró pronto la fórmula para hacer frente al populismo de los zorrillistas. La postura anticlerical de éstos, su vinculación a la masonería y su teórico apoyo a las reivindicaciones de los obreros les dejó abiertamente enfrentados a los católicos. El catolicismo como actitud será desde entonces el eje de la política de la derecha más conservadora, a falta de ideología propia más eficaz.

La estrategia de las Ligas Católicas, aprobada en el Congreso Católico de Burgos

\footnotetext{
${ }^{21}$ Cf. El Heraldo de Castellón (2-V-1901) 2.

${ }^{22}$ PÉREZ ARRIBAS, E.: Politics i cacics .... op. cit. pp. 18 y 24.
} 
de 1891, fracasó en la mayor parte de España por la oposición que encontraron entre los partidos dinásticos. Sin embargo, tuvo éxito en aquellos lugares donde los republicanos detentaban la hegemonía ${ }^{23}$. En el distrito de Castelló los católicos seguidores del padre Vicent y un sector de los Integristas hicieron causa común con el partido Liberal y los carlistas contra la coalición cossi-republicana, convertida en el adalid del sentimiento liberal de Castelló. La paradoja de que los canovistas apoyen a los zorrilistas, mientras los sagastinos se unían a los carlo-católicos sólo puede ser explicada tras rastrear los orígenes de los componentes de ambos partidos en la provincia y comprobar que, si los Conservadores procedían en su mayoría de las filas del antiguo Progresismo, los Liberales, -al menos su fracción principal en los años noventa-, procedían del carlismo, del desaparecido partido Moderado y de la sección no tetuanista del partido Conservador ${ }^{24}$.

El bloque carlo-católico-Liberal encontró su principal apoyo en la masa de propietarios agrarios de Castelló y, sobre todo, del resto de poblaciones, entre las que destacó por su beligerancia Vila-real. Este colectivo social siempre vio a los republicanos como defensores de los intereses de las clases urbanas y poco dedicados a proteger al mediano y pequeño propietario agrario. Un exponente de la evolución de su comportamiento político lo constituyó el Círculo de Labradores de Castelló, dirigido por José Sánchez Esteller, director, al mismo tiempo, de la publicación $L a$ Hoja Suelta, donde puede apreciarse su antirrepublicanismo y su aproximación a las corrientes católico-liberales.

A partir de la última década del siglo la instrumentación del factor religioso fue fundamental para la movilización de las fuerzas más conservadoras. Uno de los actos de propaganda católica más importante del período tuvo lugar en 1899 . Se trató de la romería al sepulcro de San Pascual, en Vila-real, que convocó a sesenta mil peregrinos. La iniciativa se enmarcaba en el contexto del pontificado de León XIII, defensor del catolicismo social y artífice de la elevación del santo a Patrón Universal de los Congresos Eucarísticos. La ocasión era propicia para demostrar la unión de los obreros católicos, su alejamiento de las posturas revolucionarias y la cooperación entre la clase obrera y la patronal, cuya lueha rechazaba la Iglesia.

El auténtico organizador de esta campaña fue el presbítero y jesuita vilarrealense Antonio Faulí. Fundador del Diario de la Plana, convirtió éste en órgano oficial de la peregrinación, pero también en tribuna desde donde defender las candidaturas Liberales. Los receptores de sus ataques, tetuanistas y republicanos, criticaron la intervención de la Iglesia en la política. Pero los seguidores del duque de Tetuán tampoco fueron ajenos a esta estrategia. Con ellos colaboraba un sector importante de católicos,-pidalistas y algunos Integristas-, quienes hicieron el juego al cossi usando parecidos argumentos religiosos que sus contrarios. Por tanto, el catolicismo castellonense estaba dividido. Pero el sector mayoritario apoyó la tesis del mal menor, esbozada en el folleto "El liberalismo es pecado", del doctor Sardá y Salvany. En él se decía que era útil, "en un caso dado", la unión de las fuerzas católicas con

\footnotetext{
${ }^{23}$ REIG, R.: op. cit. p. 9.

${ }^{24}$ PÉREZ ARRIBAS, E.: Politics $i$ cacis .... op. cit. pp. 15 y 21.
} 
las de otro grupo moderado del campo liberal para combatir a la fracción más extremista del mismo ${ }^{25}$.

Por tanto, también el catolicismo como actitud contribuyó a socializar la vida política de Castelló en tanto en cuanto favoreció la movilización de la opinión. A pesar del evidente reaccionarismo de los contenidos, el electorado católico poco tenía que ver con el desmovilizado y pasivo "elector" de los partidos dinásticos. Al igual que los republicanos, llevaron a cabo campañas electorales con mítines y programas, aunque estos últimos se redujesen a apelaciones éticas y morales dirigidas a las conciencias "verdaderamente católicas". Asimismo, republicanos y católicos compartían los mismos mecanismos populistas, aunque con opuestos contenidos. Si en los primeros la idea movilizadora era el progreso socio-económico y político, para los católicos era la lucha contra la modernidad, -entendiendo como tal los efectos, perniciosos según su opinión, que el librepensamiento y el liberalismo aportaban a las costumbres y al conjunto de ideas del pueblo-. En esto encontraban la causa de la laicización creciente de la sociedad y de la pérdida de la fe. La solución estribaba en potenciar la presencia de "auténticos católicos" en la vida pública con el fin de confesionalizarla ${ }^{26}$.

La coalición de la derecha más conservadora aglutinada en torno al catolicismo no hubiera poseído nunca suficiente fuerza sin el apoyo del carlismo. Su arraigo entre las gentes que temían las innovaciones y transformaciones socio-económicas del liberalismo, -labradores principalmente-, proporcionó a la coalición una masa fiel de seguidores. Aliado incómodo, nunca supo digerir la paradoja de prestar apoyo a candidatos que, una vez diputados, estarían al servicio de Sagasta. Por ello, las posturas se irían radicalizando hasta el punto de que los Liberales presentaron candidatos muy ligados al carlismo para atraerse todo el apoyo de los tradicionalis$\operatorname{tas}^{27}$.

Pero si el carlo-catolicismo dominó con facilidad en las poblaciones del distrito de Castelló, nunca pudo influir en la capital. Así, se produjo una radical oposición entre el campo, carlo-católico y tradicionalista, y la ciudad, republicana y progresista. Se aumentó así el nivel de movilización ideológica y popular, pero también se hizo imposible el consenso. Por ello, ni republicanos ni carlo-católicos configuraron auténticos movimientos populistas, -como en un principio podía presuponerse-, ya que no lograron globalizar la representación del conjunto social. De este modo, la Restauración, que como sistema había nacido para limar conflictos y encontrar un orden pacífico en el que los partidos dinásticos se repartiesen el poder, terminó con el enfrentamiento entre dos fuerzas antagónicas que también luchaban por el poder, pero que habían quedado excluidos del turno pacífico.

La aparición de fuerzas ultraconservadoras empeñadas en defender los valores de la sociedad tradicional, prueba el hecho de que los elementos de la modernización

\footnotetext{
${ }^{25}$ Cf. Diario de la Plana (26-III-1898) 1.

${ }^{26}$ Cf. La Verdad (23-XI-1890) 2; (28-XII-1890) 2; (1-II-1891) 1-2 y (8-II-1891) 2.

${ }^{27}$ En 1901 los Liberales presentaron por el distrito de Castelló a Pedro Font de Mora, cuya familia se caracterizó por su vinculación al carlismo.
} 
presentaban la suficiente fuerza como para poder hablar de una sociedad dual en proceso de evolución. Por tanto, el sistema liberal oligárquico, característico de la vieja política, comienza a quebrarse antes de lo que sugieren autores como Mayer. Los partidos de masas van produciendo las primeras grietas en la maquinaria política monopolizada por el clientelismo, descubriendo sus debilidades. Ello provocará, lo hemos visto, reacciones de defensa de la oligarquía, que ensayará diversos modos de autoperpetuarse en el poder. Pero también traerá, como resultado final, la instauración de regímenes liberales democráticos. 